\title{
EDUCATION IN THE MAN AND SOCIETY CURRICULAR AREA
}

\author{
Gabriela KELEMEN, Ph.D., \\ Faculty of Educational Sciences, Psychology and Social Sciences, \\ Aurel Vlaicu University of Arad, \\ gabriela.kelemen@uav.ro
}

\begin{abstract}
This articleaims to highlight the importance of activities inscribed within the Man and Society curricular area, by way of showing the implications played in preparing kindergarten students for later school and especially for their social life. We shall prove that practical activities contribute to the multifaceted development of preschool children's personality.
\end{abstract}

Key words: personality; social behaviour; social abilities, attitudes;

\section{Introduction}

Pre-school level education, as integral part of the undergraduate level teaching system, aims to afford a holistic and normal development for children. The general aim of pre-school level education derives from the general scope of the national educational system and endeavours to allow each child to grow and develop in his/her own rhythm, offering support for:

- developing one`s physical and psychological potential;

-improving the capacity to interact with other children and adults;

- stimulating the child to interact with the environment, to discover it by means of exploration, trials, exercises and choices;

- aiding the child to discover his/her own identity and a positive self image;

- supporting the child in developing aptitudes necessary for future school related activities. ${ }^{2}$

1. Pre-school level education aims to fulfil several objectives by way of kindergarten activities, amongst which activities that fall under the Man and Society curricular area.

1.1. Environmental education targets in equal measures the knowledge, attitudes, values and practical endeavours related to the environment.

Environmental education has the following objectives:

- Nurturing love for the Earth as well as for all related elements: water, plants, animals etc.;

- Increasing the desire to take care, respect and protect nature by involving children in experimental and demonstrative actions;

- Developing environment related research, exploration, investigation aptitudes;

- Getting to know various beings and phenomena as well as their characteristics;

- Building vocabulary with the aid of words related to ecology;

- Developing necessary behaviours in order to ensure the balance between the individual`s, society`s and the environment`s wellbeing;

- Knowing the protected plants and animals;

- Researching the ways to rehabilitate the environment by engaging pupils in waste management and various other ecological cleaning activities;

- Understanding the need to save water, electricity, wood etc. (all natural resources);

- Forming a disapproving attitude towards all who violate ecological laws and norms.

${ }^{2}$ Tomsa Ghe., Psihopedagogie prescolara si scolara,MEC, Bucuresti, 2005 
1.2. Education for work is distinguished by a new conception regarding general and particular objectives, and, even for pre-school level it stipulates the following:

- Development of practical self-serving skills, and communal work habits (in classrooms, hallways, locker rooms, yards)

- Practical work abilities, maintaining order at the work place as well as playgrounds, taking care of plants.

- Developing autonomy in daily activities such as: washing, dressing, ordering materials needed for various activities

- Developing notions and representations regarding the family, home, the street children live on, people`s work and social relations pertaining to the work process

- Getting familiarized with certain areas of activity and associated work tools.

- Getting familiarized with simple work practices and handling tools such the hammer, scissors, pliers, shovel etc.

- Educating the respect towards work, the respect towards working people, the respect towards the public domain

- Training towards an effective participation in various work areas according to their abilities

- Accomplishing practical tasks inspired by nature, daily life or imagination and based on a pre-chosen topic either decided upon by the tutor or the child, using available materials and contributing towards the embellishment of the ambient environment.

- Developing motor skills in using tools and objects

In conclusion kindergarten specific activities try to channel the pre-school children towards knowledge, education and successful integration in school and social activities in order for the pre-school child to successfully face latter, school related challenges. Once positive work attitudes are successfully formed the pre-school child will have a smoother transition from kindergarten games to learning activities he/she will face in school.

1.3. Education for peace and cooperation is the safest way to eliminate aggression, violence, terrorism and conflict between communities. It represents a factor able to contribute towards the creation of a democratic society. Peace is an aspiration, a fundamental imperative of our age and an educational priority of today's and tomorrow's education. "With all the differences between continents and countries, with all cultural and ideological differences, the finality of the fight for a better future is the same everywhere. Protecting peace isa universal desire similarly to that of ensuring basic education for all people, to eradicating hunger and protecting health, defending nature, saving the cultural identity of different human

Education for peace can be efficient on a socio-politic level only if it spreads simultaneously in every country, based on common trust and fundamental common objectives. Educational objectives regarding peace can be divided into 3 main categories:

- To develop concepts as well as area specific knowledge: peace and education for peace, disarmament and education for disarmament, democracy and human rights, cooperation, universal culture and national cultures, final and instrumental values, contemporary issues and possible solutions, bridging the past to the future and present, the distinction between pacifists and peace builders, conflict and conflicting feelings, fanatics and believers etc.

\footnotetext{
${ }^{3}$ Bogdan Suhodolski- Polish philosopher
} 
- To develop abilities and aptitudes: to listen, to conduct a dialogue, to propose and offer answers, to faithfully communicate one's own opinions or intentions, to initiate change and control them, to continuously develop etc.

- To develop behaviours and attitudes: responsibility towards one's country, solidarity and trust in mankind, respect towards other cultures, tolerance i.e. accepting diversity and generosity, moral and intellectual integrity, respect towards spiritual values, modesty, critical spirit and the ability to make decisions.

\subsection{Human rights education (EDDO)}

EDDO objectives, like any other educational segment refer to: knowledge transfer, fostering aptitudes and developing attitudes.

EDDO related knowledge target rights, liberties, obligations and responsibilities; various field specific international instruments, organizations and institutions; various forms of inequality, discrimination, significant developments registers during the past and present of establishing human rights, principles, values, institutions and mechanisms specific to democracy.

Within EDDO, the following can be developed:

- Intellectual aptitudes:

- written and oral expression, the ability to have a dialogue, to listen and argue one's opinions;

- collecting, selecting, synthesising and analysing information from different sources and developing objective and balances conclusions;

- identifying and refusing preconceptions, stereotypes and discrimination.

- Social aptitudes:

- recognizing and accepting differences;

- establishing positive and un-oppressive personal relationships;

- peaceful conflict resolution;

- accepting responsibilities;

- partaking in the decision making process;

- understanding and using human rights defence mechanisms at local, regional and European/worldwide levels .

Some of the EDDO targeted attitudes are: self respect and trust in one's own potential, understanding the problems of others (empathy) or the group's (solidarity), responsibility for one's own actions and respect towards social order, rebuttal of discriminations and abuse in other words civic values based on general human moral values.

1.5.Education for communication and mass-mediaincludes forming and developing abilities for the cultural capitalization of media information, developing civic spirit as well as of the means that must be used to understand such aims.

\subsection{Health education}

School level health education represents one of the main ways to promote correct knowledge pertaining to the various aspects of general health as well as to form necessary attitudes and habits for responsible and healthy behaviour. In several countries health education is compulsory in schools starting from kindergarten until the end of high school, each study cycle relying on appropriate health education materials. There are several arguments that can be brought forth to highlight the importance of health education within schools:

- first of all, one of the main aims of the educational system is to pass along sanctioned information from different fields of science and culture alongside with the development of 
practical abilities. Health education as part of medical sciences aims not only to transmit correct scientific information but also to create healthy individual behaviours, attitudes that are in line with the educational ideal.

- The school is an ideal place to disseminate these types of information, for no other institution has the ability and capacity to encompass and to address such a high population percentage.

- One of the essential elements for reaching a desired outcome is to initiate and develop health related educational programmes from an early age. Preventive behaviour thus becomes a habit, one that exists alongside educational development. For a grown person the impact of such programmes is always of lesser consequence compared to someone who was initiated at an early age.

- At the same time school represents an institution with a great moral authority, offering a framework for formal, informal and non-formal education; more to the point, academic subjects develop a higher importance (at an individual psychological level) compared to those subjects which are not included in a curriculum.

Of course that other types of education that have emerged in the contemporary educational system could be analyzed, however I chose only the few which appear to be more tightly connected to each other, especially considering the topic developed in the next chapter. I assert this because a positive work attitude cannot exist outside a proper attitude towards the environment, people around us and our own self. All of these cannot be accomplished without the different types of educations mentioned earlier. ${ }^{4}$

\section{Research methodology}

\subsection{Research Objectives}

The study of differences between the subjects of Group 1 and Group 2 (each group consists of pre-school children). The study of the correlation between performances registered during the psychological tests.

Optimizing the performances registered during the psychological tests by way of training.

\subsection{Hypotheses}

1. There are significant differences between subjects belonging to group 1 and 2 due to the intense involvement of group 1 pre-school children in the Man and Society curricular area.

2. The performances registered during the psychological tests $(x 1, x 2, x 3)$ are correlating.

3. The performances registered during the psychological tests can be improved after partaking in a training session.

\subsection{Design}

Hypothesis no. 1. V.I.-A- subjects

a1- group 1

a2- group 2

$$
\text { V.D.- } \mathrm{x} \text { - test scores }
$$

x1- W.I.S.C.

x2 - Rey

x3- Inventory

\begin{tabular}{|l|l|l|l|}
\hline A & $x 1$ & $x 2$ & $x 3$ \\
\hline a1 & & & \\
\hline a2 & & & \\
\hline
\end{tabular}

Unifactorial inter-subjective design

${ }^{4}$ Sas Cecilia, idem 
Hypothesis no. II. V.D.- $\mathrm{x}$ - test scores

x1- W.I.S.C

x2- Rey

x3- Inventory

\begin{tabular}{|l|l|l|l|}
\hline $\mathrm{x}$ & $\mathrm{x} 1$ & $\mathrm{x} 2$ & $\mathrm{x} 3$ \\
\hline & & & \\
\hline
\end{tabular}

Correlational design

Hypothesis no. III. V.I. - A- moment of testing

a1- pre-test

a2- post-test

V.D.-x vocabulary development

\begin{tabular}{|l|c|}
\hline A & $x$ \\
\hline a1 & \\
\hline a2 & \\
\hline
\end{tabular}

Unifactorial inter-subjective design

\subsection{Subjects description}

- The total number of subject is $60 ; \mathrm{N}=60$

- The subjects are divided into two sample groups of 30 pre-school children each, age group between 5-7 years.

- The first sample group consists of 30 pre-school children $(\mathrm{n} 1=30)$

- The second sample group consists of 30 pre-school children

2.5. Description of tests applied:

- W.I.S.C test.

- A. Rey memorization test

- trial inventory to determine the psychological age of language I

„Competent test users are and must be always aware of the limits that the instruments used provide and, at the same time, they must know the way in which these can be compensated through other information sources pertaining to the subject" (Mitrofan, Mitrofan, p.18, 2005).

\section{- The W.I.S.C. test}

The W.I.S.C. battery test includes verbal tests (that imply the usage of language) and non-verbal tests (issues can be solved without the involvement of speech). The latter are defined as "performance tests". $\underline{\text { Verbal }}$

1. Vocabulary

2. Arithmetic

3. General comprehension

4. Similitude

5. General Information

\section{$\underline{\text { Performance }}$}

1. Image filling in

2. Cubes

3. Image sorting

4. Code B.

5. Object assembly

The study relies only on the vocabulary test. This trial is composed of 40 words. Assessment is made by granting 1 or 0 for each word. The maximum number of points achievable is 40 . 


\begin{tabular}{|l|l|l|l|l|l|}
\hline 1. Dog & 11. Sloth & 21. Tasty & 31. Dress & \\
\hline 2. Candy & 12. Soup & 22. To finish & 32. Valid & \\
\hline 3. Mailman & 13. Snowdrop & 23. Angry & 33. To return & \\
\hline 4. Hammer & 14. Pill & 24. Tea pot & 34. Closet & \\
\hline 5. Plug & 15. Carriage & 25. Hypocrite & 35. Confusion & \\
\hline 6. Carrot & 16. Bookstore & 26. Lock & 36. Jubilant & \\
\hline 7. Truck & 17. Gum & $\begin{array}{l}\text { 27. Brother - in- } \\
\text { Law }\end{array}$ & 37. Narration & \\
\hline 8. Knife & 18. Lining & 28. Fuel & 38. Crenel & \\
\hline 9. Pebbles & 19. Landmark & 29. Fence & 39. Dawn & \\
\hline 10. Winter & 20. Beam & & 30. Indifferent & 40. Airtight & \\
\hline
\end{tabular}

\section{- $\quad$ A.Rey memorization test}

The inventory targets children aged from 3 to 7 years of age and consists of 7 trials that allow the identification of deviances in the development of language in accord with chronological age.

\subsection{Testing procedure}

The training, including an optional course with activities related to the Man and Society curricular area has been applied to group 1 during 10 distinct activities.

\section{Activity 1}

Activity objectives

After undergoing the activity, children will be able to:

- To establish in accord with the supervisor, the training's objectives;

- To establish certain rules to be followed during the training period.

$\underline{\text { Activities }}$

- Short overview - I introduce myself, then I ask the children to do the same;

- Establishing the date of the next meeting (2 hours per week).

Evaluation

- Some of the established training's objectives are enumerated.

\section{Activity 2}

\section{Activity objectives}

- establishing and activating the vocabulary regarding certain words (adjectives, nouns) with an opposite meaning;

- perfecting the correct formulation and the meaning of the sentences;

\section{$\underline{\text { Activities }}$}

- the game "Answer quickly and correctly!"

- finding antonyms for some of the words used and forming sentences;

- using images containing elements that suggest an antonym: short pencil - long pencil, full basket - empty basket, happy child - sad child etc. When indicating an image the child is to name it and enounce its antonym;

- for the end of the game, we have introduced movement based applied elements: I raised my hands up - the child lowered his arms, I turned to the right - the child turned to the left; I walked forward - the child moved back.

Evaluation

- Verification of the way the image is named as well a show the antonym is used;

- Formulation of a sentence with the antonym. 


\section{Activity 3}

Activity objectives

- developing the ability to form complete sentences referring to everyday items, to identify

and to present their personal hygiene usage;

- activating logical thinking by identifying corresponding words.

Activity

- the game"Fill in the missing part!"

- completing a sentence with the missing part

Evaluation

- Forming complete sentences by identifying the appropriate missing word.

\section{Activity 4}

- Activity objectives

- Verifying and consolidating behaviour patterns in a shop;

- Educating correctness in paying and standing in line;

- The ability to identify the larger number (1-10: is greater than 1, therefore 500 I sgreater than 100).

Activity

- playing"Shop";

- Correct usage of polite greetings from the moment of entering the shop until the end of the visit;

- Counting from 1 to 10 and backwards from 5 to 1 ;

- Discovering the missing number from a string of numbers;

- Using money (play money) within the role play game;

- Discovering related numbers for a given one (ex. for 3, identify 2 and 4) ;

- Correct identification and naming of an ordinal number (in a string consisting of 3,5,7,9 he/she is to identify the middle number as the first, the second, the third etc.)

Evaluation

- Verifying the correct placement of a number between 1 and 10 within an ascending and descending order);

- Understanding the value of an object by means of money;

\section{Activity 5}

- Activity objectives

- Recognizing materials (metal, glass, plastic, paper etc.) used in making objects.;

- Developing tactile sensitivity.

Activity

- the game "Say what it's made of!"

- We have introduced several small objects in a bag. The child must reach inside without looking and by feeling the object must identify what it is made of. Then he/she is to take it out and name it.

- Evaluation

- Verifying that the child recognizes the objects and names them correctly.

- Activity 6

- Activity objectives

- To consolidate their counting technique by use of their tactile sense;

- To determine the value of a number by counting.

- Activity

-the game "Close your eyes and count"

- the child shall wear a scarf covering his eyes and will be handed a basket with a varying number of beads. The child must count the beads while extracting them from one basket and placing them in another. 
- verifying correct counting.

\section{Activity 7}

- Activity objectives

- Verifying the child's knowledge regarding some well known colours: white, yellow, red, green, purple, maroon, blue, black;

- The child`s capacity to respond to the game coordinator by direct action.

Activity

- the game "Small boats are coming!"

- 15 children take part;

- the imaginary lake is a circle, drawn with blue chalk. Each child receives a different colour boat. At the raising of a flag (with colours corresponding to the boats) the child who has the right colour boat will place his boat on the lake. If a mistake is made the rest of the group will correct the child.

Evaluation

- Verifying colour related knowledge.

\section{Activity 8}

- Activity objectives

- Developing the ability to form sentences using correct present tense verbs;

- Vocabulary building with words expressing action;

- Educating the possibility to perceive movement in a different ways and to link the object to the action.

Activity

- the game "What am I doing?"

- The child verbally expresses the action named.

Evaluation

- Expressing in short sentences the perceived action.

\section{Activity 9}

- Activity objectives

- To name animal cubs;

- To use their names correctly;

- The ability to use the genitive and dative cases;

- Emphasising the motherls care towards her cub.

Activity

- the game "What's good, what's wrong", the child names and recognizes adequate (polite) behaviour related actions.

Evaluation

- Recognizing adequate and inadequate behaviour based on drawings.

\section{Activity 10}

- Activity objectives

- To use comparisons between drawings and to select them according to similitude and differences;

- To strengthen analysis and comparison abilities;

- To develop powers of observation.

Activity

- Each child receives a file containing images of objects and characters from fairytales they know; they must identify negative and positive characters and must identify the characteristics of socially adequate behaviour;

- Each image appears 3 times and the all identical images must be found and coloured with a different (indicated) colour.

\section{Evaluation}


- Respecting the narrative of the story in addition to observing the way the child solves the exercise.

\subsection{First Hypothesis}

\section{Data and results analysis}

There are significant differences between subjects in group 1 and 2 from the perspective of vocabulary development.

In order to process the data we have relied on the SPSS 10, 0 statistical-mathematical computer programme.

To highlight the existing differences between the two pre-school groups (Romanian and foreign language based kindergartens) the main tendency and spread factors have been calculated for each group of children in regards of the total score.

After interpreting the data the following descriptive results have been found for W.I.S.C. (Wechsler Intelligence Scale for Children), A.Rey and inventory (Sample inventory for the assessment of the psychological age of language) tests. The descriptive processing of data has been conducted for both sample groups and the average values registered are represented in the table below:

Tabel 1. Indicators for the main tendency for group 1 - Romanian language kindergarten

\begin{tabular}{|c|c|c|c|c|c|c|c|c|}
\hline & W.I.S.C & Rey1 & Rey2 & Rey3 & Rey4 & Rey5 & Rey6 & Inventar \\
\hline $\mathrm{N}$ & 30 & 30 & 30 & 30 & 30 & 30 & 30 & 30 \\
\hline Media & 20.50 & 6.23 & 6.96 & 7.30 & 8.53 & 9.53 & 10.23 & 6.10 \\
\hline Mediana & 20.00 & 6.00 & 6.50 & 7.00 & 8.00 & 9.00 & 10.00 & 6.00 \\
\hline Ab. standard & 2.84 & 1.47 & 1.65 & 1.41 & 2.30 & 2.06 & 1.86 & 0.71 \\
\hline Minimum & 15.00 & 4.00 & 5.00 & 5.00 & 5.00 & 7.00 & 7.00 & 5.00 \\
\hline Maximum & 28.00 & 9.00 & 12.00 & 11.00 & 14.00 & 14.00 & 14.00 & 7.00 \\
\hline
\end{tabular}

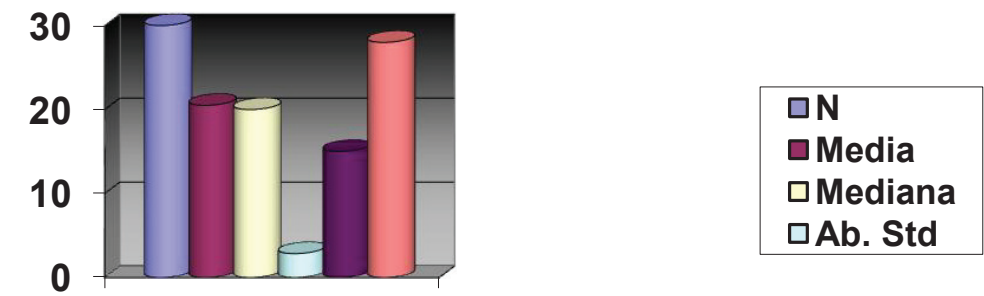

W.I.S.C.

Diagram no. 1.- Statistical results based on the W.I.S.C test, group 1

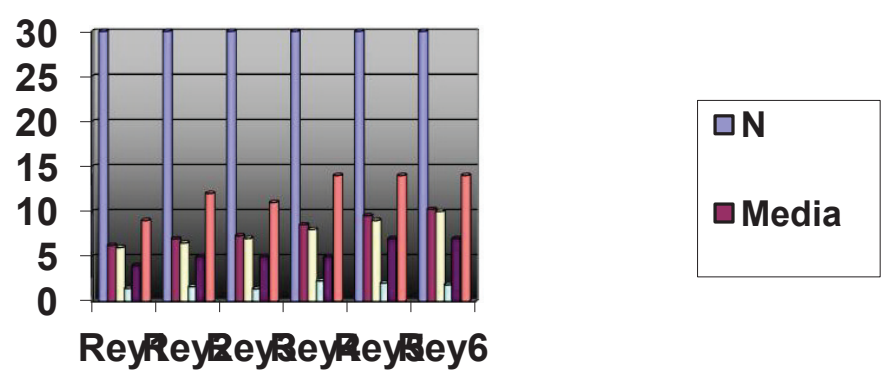

Diagram no. 2. - Statistical results based on the Ray test, group 1 


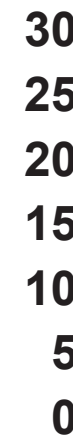

30
25
20
15
10
5
0

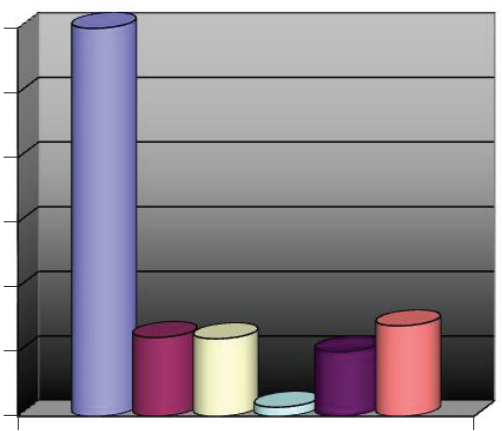

$\square \mathbf{N}$
$\square$ Media
$\square$ Mediana
$\square$ Ab. Std
$\square$ Min
$\square$ Max

Inventar

Diagram no. 3. - Statistical results based on the sample trial inventory for group 1

Table 2. Indicators for the main tendencies for group 2

\begin{tabular}{|c|c|c|c|c|c|c|c|c|}
\hline & W.I.S.C & Rey1 & Rey2 & Rey3 & Rey4 & Rey5 & Rey6 & Inventar \\
\hline $\mathrm{N}$ & 30 & 30 & 30 & 30 & 30 & 30 & 30 & 30 \\
\hline Media & 20.00 & 6.46 & 7.06 & 7.23 & 7.80 & 9.16 & 10.10 & 6.00 \\
\hline Mediana & 19.00 & 6.00 & 7.00 & 8.00 & 8.00 & 9.00 & 10.00 & 6.00 \\
\hline Ab.standard & 3.07 & 1.38 & 1.38 & 1.56 & 1.75 & 1.44 & 1.37 & 0.64 \\
\hline Minimum & 14.00 & 4.00 & 5.00 & 5.00 & 4.00 & 6.00 & 7.00 & 5.00 \\
\hline Maximum & 28.00 & 9.00 & 10.00 & 10.00 & 11.00 & 12.00 & 13.00 & 7.00 \\
\hline
\end{tabular}

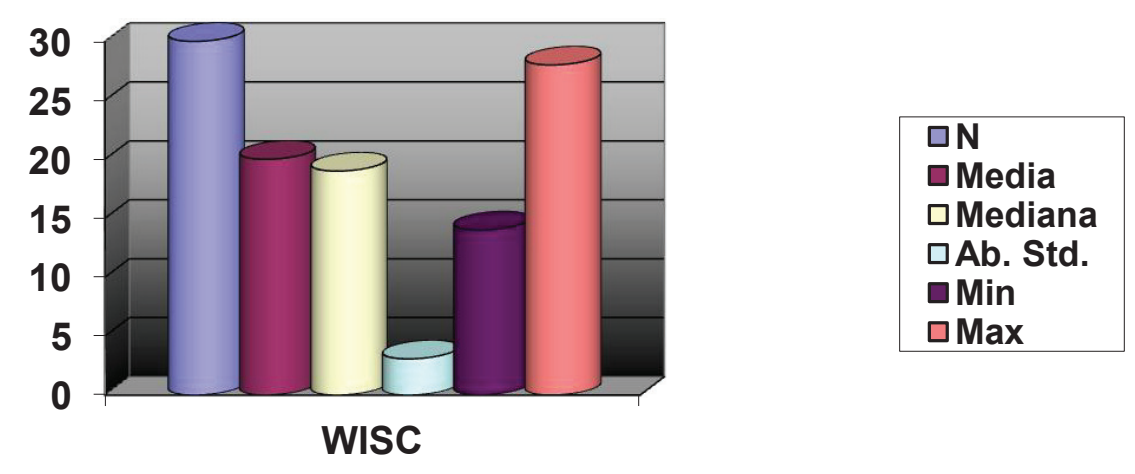

Diagram no. 4. - Statistical results based on the W.I.S.C test for group 2.

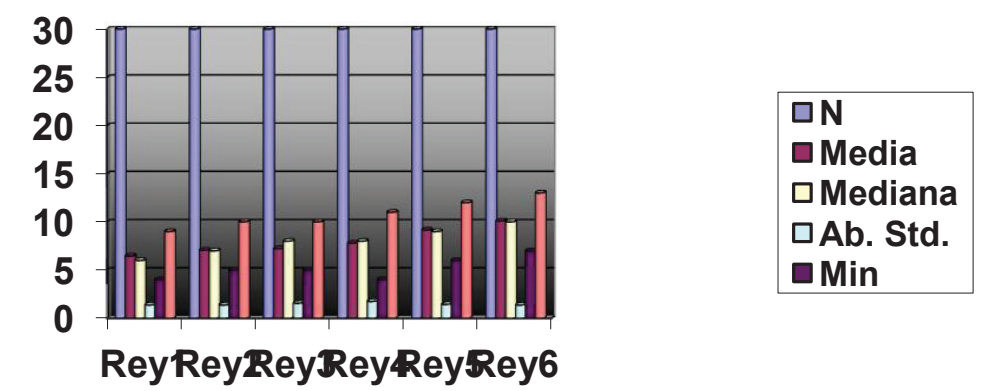

Diagram no.5. - Statistical results based on the Ray test for group 2 

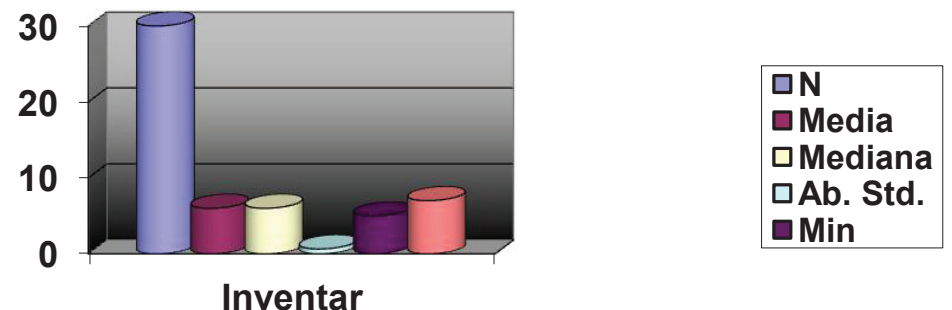

Diagram no. 6. - Statistical results obtained following the evidence inventory for Group 2

Based on the descriptive data from the three trials it becomes obvious that there are differences between the two sample groups. The comparisons regarding the significance of the differences between the two sample groups (group 1 pre-school children and group 2 preschool children) have been based on the $t$ test independent samples, the distribution being symmetrical.

Table 3. T test results:

\begin{tabular}{|c|c|c|c|}
\hline & T & Df & P \\
\hline Rey1 & 34.54 & 59 & 0 \\
\hline Rey2 & 35.93 & 59 & 0 \\
\hline Rey3 & 37.95 & 59 & 0 \\
\hline Rey4 & 30.58 & 59 & 0 \\
\hline Rey5 & 40.82 & 59 & 0 \\
\hline Rey6 & 48.37 & 59 & 0 \\
\hline W.I.S.C & 53.52 & 59 & 0 \\
\hline Inventory & 69.46 & 59 & 0 \\
\hline
\end{tabular}

There are significant differences between the two groups in regards of the Rey test, dimension $1(\mathrm{t}(59)=34.54, \mathrm{p}=0.00<0,05$; Rey test, dimension $2(\mathrm{t}(59)=35.95, \mathrm{p}=0.00<0,05$; Rey test, dimension $3(\mathrm{t}(59)=37.95, \mathrm{p}=0.00<0.05$;

Rey test, dimension $4(\mathrm{t}(59)=30.58, \mathrm{p}=0.00<0.05$; Rey test, dimension $5(\mathrm{t}(59)=40.82$, $\mathrm{p}=0.00<0.05$; Rey, dimension $6(\mathrm{t}(59)=48.37, \mathrm{p}=0.00<0.05$;

W.I.S.C test $(\mathrm{t}(59)=53.52, \mathrm{p}=0.00<0.05$; inventory $(\mathrm{t}(59)=69.46, \mathrm{p}=0.00<0.05$.

These results prove that there are differences between the two groups.

\subsection{Second Hypothesis}

The study of correlations based on the performances obtained during the psychological testing

The Pearson correlation coefficient has been used in order to observe the correlations between the tests applied in this study, the data distribution being symmetrical.

Table 4. Correlations based on the vocabulary trials

\begin{tabular}{|c|c|c|c|c|c|c|c|}
\hline & Rey1 & Rey2 & Rey3 & Rey4 & Rey5 & Rey6 & W.I.S.C \\
\hline Rey1 R & $\mathbf{1 . 0 0}$ & $\mathbf{0 . 7 2 * *}$ & $\mathbf{0 . 5 0 * *}$ & $\mathbf{0 . 5 6} * *$ & $\mathbf{0 . 5 2} * *$ & $\mathbf{0 . 5 5 * *}$ & 0.21 \\
P & $\mathbf{0 . 0 0}$ & $\mathbf{0 . 0 0}$ & $\mathbf{0 . 0 0}$ & $\mathbf{0 . 0 0}$ & $\mathbf{0 . 0 0}$ & $\mathbf{0 . 0 0}$ & 0.10 \\
$\mathrm{~N}$ & $\mathbf{6 0}$ & $\mathbf{6 0}$ & $\mathbf{6 0}$ & $\mathbf{6 0}$ & $\mathbf{6 0}$ & $\mathbf{6 0}$ & 60 \\
\hline Rey2 R & $0.72 * *$ & $\mathbf{1 . 0 0}$ & $\mathbf{0 . 6 7 * *}$ & $\mathbf{0 . 7 1} * *$ & $\mathbf{0 . 6 2} * *$ & $\mathbf{0 . 6 1} * *$ & 0.23 \\
$\mathrm{P}$ & 0.00 & $\mathbf{0 . 0 0}$ & $\mathbf{0 . 0 0}$ & $\mathbf{0 . 0 0}$ & $\mathbf{0 . 0 0}$ & $\mathbf{0 . 0 0}$ & 0.07 \\
$\mathrm{~N}$ & 60 & $\mathbf{6 0}$ & $\mathbf{6 0}$ & $\mathbf{6 0}$ & $\mathbf{6 0}$ & $\mathbf{6 0}$ & 60 \\
\hline Rey3 R & $0.50 * *$ & $0.67 * *$ & $\mathbf{1 . 0 0}$ & $\mathbf{0 . 6 1} * *$ & $\mathbf{0 . 4 6 * *}$ & $\mathbf{0 . 4 3} * *$ & $0.30 *$ \\
$\mathrm{P}$ & 0.00 & 0.00 & $\mathbf{0 . 0 0}$ & $\mathbf{0 . 0 0}$ & $\mathbf{0 . 0 0}$ & $\mathbf{0 . 0 0}$ & 0.02 \\
$\mathrm{~N}$ & 60 & 60 & $\mathbf{6 0}$ & $\mathbf{6 0}$ & $\mathbf{6 0}$ & $\mathbf{6 0}$ & 60 \\
\hline Rey4 R & $0.56^{* *}$ & $0.71 * *$ & $0.61 * *$ & $\mathbf{1 . 0 0}$ & $\mathbf{0 . 6 8} * *$ & $\mathbf{0 . 6 4} * *$ & 0.18 \\
$\mathrm{P}$ & 0.00 & 0.00 & 0.00 & $\mathbf{0 . 0 0}$ & $\mathbf{0 . 0 0}$ & $\mathbf{0 . 0 0}$ & 0.16 \\
\hline
\end{tabular}




\begin{tabular}{|c|c|c|c|c|c|c|c|}
\hline $\mathrm{N}$ & 60 & 60 & 60 & $\mathbf{6 0}$ & $\mathbf{6 0}$ & $\mathbf{6 0}$ & 60 \\
\hline Rey5 R & $0.52^{* *}$ & $0.62^{* *}$ & $0.46^{* *}$ & $0.68^{* *}$ & $\mathbf{1 . 0 0}$ & $\mathbf{0 . 8 3} * *$ & 0.18 \\
$\mathrm{P}$ & 0.00 & 0.00 & 0.00 & 0.00 & $\mathbf{0 . 0 0}$ & $\mathbf{0 . 0 0}$ & 0.15 \\
$\mathrm{~N}$ & 60 & 60 & 60 & 60 & $\mathbf{6 0}$ & $\mathbf{6 0}$ & 60 \\
\hline Rey6 R & $0.55^{* *}$ & $0.61^{* *}$ & $0.43^{* *}$ & $0.64 * *$ & $0.83^{* *}$ & $\mathbf{1 . 0 0}$ & 0.18 \\
$\mathrm{P}$ & 0.00 & 0.00 & 0.00 & 0.00 & 0.00 & $\mathbf{0 . 0 0}$ & 0.15 \\
$\mathrm{~N}$ & 60 & 60 & 60 & 60 & 60 & $\mathbf{6 0}$ & 60 \\
\hline WISC R & 0.21 & 0.23 & $0.30^{*}$ & 0.18 & 0.18 & 0.18 & $\mathbf{1 . 0 0}$ \\
P & 0.10 & 0.07 & 0.02 & 0.16 & 0.15 & 0.15 & $\mathbf{0 . 0 0}$ \\
N & 60 & 60 & 60 & 60 & 60 & 60 & $\mathbf{6 0}$ \\
\hline
\end{tabular}

** Significant correlation at a 0,01 threshold

* Significant correlation at a 0,05 threshold

\subsection{Third Hypothesis}

\section{Optimizing results gathered from psychological tests by way of training}

After the descriptive processing of gathered results (the following data has been obtained for the Ray, W.I.C.S. test as well as for the inventory) based on the occurrences of the test: pre and post test (after the completion of the training).

The comparison has been made using the $t$ tests for pairs.

Table 5. Rey test comparison results, group 1

\begin{tabular}{|c|c|c|c|}
\hline & Media & $\mathbf{N}$ & $\mathbf{P}$ \\
\hline Per1 PostRey1 PreRey1 & $\begin{array}{l}6.23 \\
5.96\end{array}$ & 30 & 1.47 \\
\hline Per2 PostRey2 PreRey2 & $\begin{array}{l}6.96 \\
4.93\end{array}$ & $\begin{array}{l}30 \\
30\end{array}$ & $\begin{array}{l}1.65 \\
2.05\end{array}$ \\
\hline Per3 PostRey3 PreRey3 & $\begin{array}{l}7.30 \\
6.53\end{array}$ & $\begin{array}{l}30 \\
30\end{array}$ & $\begin{array}{l}1.41 \\
2.11\end{array}$ \\
\hline Per4 $\quad$ PostRey4 PreRey4 & $\begin{array}{l}8.53 \\
6.93\end{array}$ & $\begin{array}{l}30 \\
30\end{array}$ & $\begin{array}{l}2.30 \\
2.14\end{array}$ \\
\hline Per5 $\quad$ PostRey5 PreRey5 & $\begin{array}{l}9.53 \\
7.70\end{array}$ & $\begin{array}{l}30 \\
30\end{array}$ & $\begin{array}{l}2.06 \\
1.93\end{array}$ \\
\hline Per6 PostRey6 PreRey6 & $\begin{array}{c}10.23 \\
8.83\end{array}$ & $\begin{array}{l}30 \\
30\end{array}$ & $\begin{array}{l}1.86 \\
1.83\end{array}$ \\
\hline
\end{tabular}

Table 6. Rey test comparison results,group 2

\begin{tabular}{|ll|c|c|c|}
\hline & & Media & N & P \\
\hline Per1 & PostRey1 PreRey1 & 6.43 & 30 & 1.38 \\
& & 5.90 & 30 & 1.47 \\
\hline Per2 & PostRey2 PreRey2 & 7.06 & 30 & 1.38 \\
& & 6.16 & 30 & 2.01 \\
\hline Per3 & PostRey3 PreRey3 & 7.23 & 30 & 1.56 \\
& & 5.90 & 30 & 1.64 \\
\hline Per4 & PostRey4 PreRey4 & 7.80 & 30 & 1.76 \\
& & 5.63 & 30 & 1.58 \\
\hline Per5 & PostRey5 PreRey5 & 9.16 & 30 & 1.44 \\
& & 7.86 & 30 & 1.37 \\
\hline Per6 & PostRey6 PreRey6 & 10.10 & 30 & 1.43 \\
\hline
\end{tabular}

Judging from the gathered data there are significant differences between the timing of the two tests

Table 7. The significance of the differences between the two testing periods, for the Rey trial, group 1

\begin{tabular}{|l|l|l|} 
T & Df & P \\
\hline
\end{tabular}




\begin{tabular}{|l|l|l|l|}
\hline Per1 PostRey1PreRey1 & 5.58 & 29 & 0.00 \\
\hline Per2 PostRey2 PreRey2 & 5.83 & 29 & 0.00 \\
\hline Per3 PostRey3 PreRey3 & 6.96 & 29 & 0.00 \\
\hline Per4 PostRey4 PreRey4 & 6.43 & 29 & 0.00 \\
\hline Per5 PostRey5 PreRey5 & 6.32 & 29 & 0.00 \\
\hline Per6 PostRey6 PreRey6 & 4.69 & 29 & 0.00 \\
\hline
\end{tabular}

For the first pre-school group, which attends a Romanian language kindergarten we have obtained the following results:

Table 8. The significance of the differences between the two testing periods, for the Rey trial, group 2

\begin{tabular}{|c|c|c|c|}
\hline & $\mathbf{T}$ & Df & $\mathbf{P}$ \\
\hline Per1 PostRey1 PreRey1 & 10.21 & 29 & 0.00 \\
\hline Per2 PostRey2 PreRey2 & 6.65 & 29 & 0.00 \\
\hline Per3 PostRey3 PreRey3 & 8.08 & 29 & 0.00 \\
\hline PostRey4 PreRey4 & 9.70 & 29 & 0.00 \\
\hline Post Rey5 PreRey5 & 6.80 & 29 & 0.00 \\
\hline PostRey6 PreRey6 & 4.54 & 29 & 0.00 \\
\hline
\end{tabular}

For the second pre-school group, which attends a foreign language kindergarten we have obtained the following results:

Table 9. The results of comparisons between pairs for the W.I.S.C. test, group 1.

\begin{tabular}{|c|c|c|c|}
\hline & Media & N & P \\
\hline Per1 PostW.I.S.C. & 20.50 & 30 & 2.84 \\
PreW.I.S.C. & 18.36 & 30 & 3.51 \\
\hline
\end{tabular}

Table 10. . The results of comparisons between pairs for the W.I.S.C. test, group 2.

\begin{tabular}{|c|c|c|c|}
\hline & Media & N & P \\
\hline Per2 PostW.I.S.C. & 20.20 & 30 & 3.07 \\
PreW.I.S.C. & 17.40 & 30 & 3.51 \\
\hline
\end{tabular}

Judging from the gathered data there are significant differences obtained between the timings of the two tests

Table 11. The significance of the differences between the two testing periods, group 1

\begin{tabular}{|c|c|c|c|}
\hline & T & df & P \\
\hline Per1 PostWISC & 6,68 & 29 & 0.00 \\
PreWISC & 6.04 & 29 & 0.00 \\
\hline
\end{tabular}

Table 12. The significance of the differences between the two testing periods, group 2

\begin{tabular}{|c|c|c|c|}
\hline & T & df & P \\
\hline Per2 PostWISC & 7,61 & 29 & 0.00 \\
PreWISC & 7,35 & 29 & 0.00 \\
\hline
\end{tabular}

Table 13. The result of comparisons amongst pairs for the inventory, group 1

\begin{tabular}{|c|c|c|c|}
\hline & T & df & Standard deviation \\
\hline Per1 PostInv. & $\mathbf{6 . 1 0}$ & $\mathbf{3 0}$ & $\mathbf{0 . 7 1}$ \\
PreInv. & $\mathbf{5 . 9 6}$ & $\mathbf{3 0}$ & $\mathbf{0 . 5 0}$ \\
\hline
\end{tabular}


Table 14. The result of comparisons amongst pairs for the inventory, group 2

\begin{tabular}{|c|c|c|c|}
\hline & T & df & Standard deviation \\
\hline Per2 PostInv. & $\mathbf{6 . 0 0}$ & 30 & 0.64 \\
PreInv. & $\mathbf{6 . 4 3}$ & 30 & $\mathbf{0 . 6 7}$ \\
\hline
\end{tabular}

From analyzing the acquired data it is obvious that there are significant differences between the two testing periods.

Table 15 The significance of the differences between the two testing periods, group 1

\begin{tabular}{|c|c|c|c|}
\hline & T & df & P \\
\hline Per1 PostInv. & 5.03 & 29 & 0.00 \\
PreInv. & 4.84 & 29 & 0.00 \\
\hline
\end{tabular}

Table 16. The significance of the differences between the two testing periods, group 2

\begin{tabular}{|c|c|c|c|}
\hline & T & df & P \\
\hline Per2 PostInv. & 4.17 & 29 & 0.00 \\
PreInv. & 4.05 & 29 & 0.00 \\
\hline
\end{tabular}

\section{Conclusions}

The kindergarten level instructional-educational process pertaining to the Man and Society curricular area of activities combines in a logical manner, elements of learning and day-to- day practical aspects. The present study wishes to highlight the way in which preschool level personality development can be optimized based on a training that consist of numerous practical activities aimed at developing an adequate social behaviour as well as of some proper practical attitudes in reply to daily occurrences. The article followed precise objectives that were inscribed in game - type activities and were followed by a specific evaluation. After verifying the hypothesis, conclusions can be drawn regarding the optimization of developing specific behaviours and social attitudes for pre-school level children based on a specific training that consists of adequate activities pertaining to the Man and Society curricular area.

Regarding the importance of the role played by the acquisition of social competences several theories have been formulated forwarding valuable contributions for the understanding of the complex aspects of social behaviour that are developed during early childhood.

As a conclusion, I'd like to accentuate the fact that the activities pertaining to the Man and Society curricular areaare very important judging from the implications of preparing pre-school children for their later social life.

\section{References:}

Creţu T., 2001, Psihologia vârstelor, Editura Credis, Bucureşti

Gherguţ A., 2005, Sinteze de psihopedagogie specială, Editura Polirom, Iaşi

Glava A., Glava C., 2002, Introducere în pedagogia preşcolară, Editura Dacia, Cluj-Napoca

Golu M., 2002, Bazele psihologiei generale, Editura Universitară, Bucureşti

Kelemen G., 2014, Metodica activităţilor instructiv educative, Editura Universităţii „Aurel Vlaicu", Arad

Mitrofan L., Mitrofan N., 2005, Testarea psihologică - Inteligenţă şi aptitudine, Editura Polirom, Iaşi

Santrock N., 2002, Life Span Development, Mc Graw Hill Companies, New-York

Verza E., 2000, Repere privind dezvoltarea cognitivă a copiilor, Revista Învăţământului preşcolar. nr 3-4 